\title{
LEAN AND SIX SIGMA METHODOLOGIES IN NHS SCOTLAND: AN EMPIRICAL STUDY AND DIRECTIONS FOR FUTURE RESEARCH
}

\author{
JIJU ANTONY, MANEESH KUMAR
}

\section{INTRODUCTION}

The quality and efficiency of manufacturing and services have been greatly improved through continuous improvement methodologies such as Lean and Six Sigma over the last 25 years or so (Antony et al., 2012; McAdam et al., 2011; Lindsay and Kumar, 2012). However the applications of such methodologies in the healthcare industry are in their infancy stages in many countries including Scotland (Lindsay and Kumar, 2012). Moreover there is substantial evidence in the application of both Lean and Six Sigma from manufacturing sector, however, there is limited empirical evidence in the current literature demonstrating the applications of these methodologies within NHS, UK.

A recent study carried out by the American Society for Quality (ASQ) has shown that the correlation between deployment of Lean and Six Sigma within 77 hospitals and improved clinical outcomes and financial performance appeared equivocal (ASQ, Lean Six Sigma Hospital Study Advisory Committee, 2009). The study has also revealed that a high percentage of hospitals, especially without Lean or Six Sigma deployments, do not track common operational metrics (length of stay and patient complaints, for example) and financial metrics (cost per patient for example).

Although the authors have identified over 200 papers relevant to Lean and Six Sigma in Healthcare, it was found that the current focus on evidence-based management to improve quality in healthcare cautions that current trends in evidence-based management are largely based on conceptual arguments and there are very few empirical studies carried out to understand the benefits of Lean and Six Sigma methodologies to improve clinical outcomes, patient safety, efficiency and financial performance. The purpose of this research was to examine the role that Lean and Six Sigma have within NHS Scotland to improve the efficiency and performance of the organization and the care provided to its patients. The study involved collecting data from a survey questionnaire distributed to various hospitals in Scotland followed by a number of semistructured interviews with people who were involved in the use of Lean and Six Sigma methodologies in the NHS Scotland. 
The remainder of the paper is structured as follows: first we provide a literature review on Lean and Six Sigma with a greater focus on empirical studies carried out by other authors in the context of healthcare, followed by the research methodology used for the research, a report on key findings and finally our conclusion and agenda for future research.

\section{LITERATURE REVIEW}

Both Lean and Six Sigma are two powerful methodologies for improving the efficiency and effectiveness of healthcare processes. Lean is based on long-held practices advanced by the Toyota Motor Corp. with an emphasis on removing waste from organisations while focusing on and delivering more value to customers. Six Sigma, coined by Motorola Corporation, focuses on the application of powerful statistical methods to understand, quantify and reduce process variation (Kumar et al., 2011). The purpose of Lean Thinking in healthcare is to create an environment for improving flow and eliminating waste. Six Sigma on the other hand, helps to identify and quantify problems that are related to variation in processes. Both are powerful strategies to focus efforts in the areas that offer the most potential improvement. Despite their disparate roots, it is quite clear that Lean and Six Sigma encompass many common features such as an emphasis on customer satisfaction, a culture of continuous improvement, comprehensive employee involvement and search for root causes. Lean always asks the question, "Why does this process exist at all? What is the value and the value stream?". Six Sigma starts with "How can we improve this process?" It does not ask "Why does it exist at all? (Antony and Banuelas, 2001).

The following are some of the commonalities and fundamental differences between Lean and Sigma methodologies (Kumar et al., 2006; Dahlgaard and Dahlgaard-Park, 2006; Snee, 2010).

Commonalities include:

- Both are continuous business process improvement methodologies

- Both focus on business needs defined by the customer

- Both are practical methods, proven to work in many organisations

- Both involve a comprehensive toolkit for tackling process related problems

Fundamental and critical differences include:

- Lean is primarily good for quick and initial round of improvements whereas Six Sigma is suitable for long-term and complex problems where the solutions are either unknown or vaguely known. 
- Lean requires low investment due to the nature of the training and the skills to be developed as a result of this training whereas Six Sigma demands high investment and is not suitable for fixing common sense problems in the business.

- Lean has less emphasis on statistical tools and techniques whereas Six Sigma requires the use of applied statistical methods for understanding and reducing variation in processes.

- No formal organizational infrastructure for Lean implementation and deployment whereas Six Sigma has a well defined organizational infrastructure (yellow belts, green belts, black belts, master black belts, deployment champions and sponsors in some cases).

- Lean looks into mapping of end to end process and uses value stream exercises to understand the interactions between processes whereas system interaction between processes is not considered in a typical Six Sigma problem solving scenario and this would possibly sub-optimize the overall process performance.

According to George (2002), Six Sigma does not directly address process speed and so the lack of improvement in lead time in companies applying Six Sigma methods alone is understandable. These companies also generally achieve modest improvement in Work in Process (WIP) and finished goods inventory turns. In a similar manner, those companies engaged in Lean methodology alone show limited improvements across the organization due to the absence of Six Sigma organizational infrastructure. In essence, an integrated approach utilizing the best of Six Sigma and Lean Strategies will maximize shareholder value by accomplishing dramatic improvements in customer satisfaction, cost, quality, speed and invested capital. The companies practicing the integrated approach will gain four major benefits (George, 2002): Become faster and more responsive to customers; strive for Six Sigma capability level; operate at lowest costs of poor quality; and achieve greater flexibility throughout the business.

In the case of a patient visiting a medical facility, it is important that the patient receives due attention at the earliest possibility in a predetermined flow. If one were implementing Lean Thinking alone, the solution could lead to very fast process in a flow, but a dissatisfied patient due to lack of attention from a physician. If one were implementing Six Sigma alone, the patient will have a great visit, but the medical facility may not be able to keep up with a required number of patients in order to be a financially viable organisation.

According to Bisgaard and De Mast (Biasgaard and De Mast, 2006), an integrated framework for Lean Six Sigma consists of the following elements:

- A structured approach - the deployment infrastructure is based on a task force consisting of champions, Black belts and Green Belts. 
- Project-based deployment-projects are classified as either "quick wins" (Lean) or "advanced" (Six Sigma). Lean projects are applied to problems associated with inventory, lead time reduction, and processing time. Typical Six Sigma projects involve problems associated with quality, defect reduction, variability reduction, yield improvement, etc.

- Organisational anchoring of solutions - to secure the implementation of solutions and guard against backsliding, tasks and responsibilities are clearly defined, procedures are standardised, etc.

- Linking project selection with business strategy - It is important to ensure that projects are aligned with the overall strategic objectives of the business

DelliFraine and Langabeer (2010) assessed the evidence of Six Sigma and Lean in the Healthcare Industry. They have conducted a structured systematic review of articles on the use of Lean and Six Sigma in healthcare settings that were published between 1999 and 2009. Of the 177 studies published during the 10 year period, it was interesting to note that $70 \%$ were related to Six Sigma, 23\% were related to Lean and $7 \%$ were related to both Lean and Six Sigma. The authors found that the level of evidence supporting a positive relationship between the use of Lean/ Six Sigma and performance improvement was weak. They also found that most studies focused on Lean / Six Sigma to improve processes of care, while few studies focused on Six Sigma/Lean to improve clinical outcomes. The authors also found limited literature on the failures of Lean/Six Sigma.

The study carried out by the ASQ Lean Six Sigma Hospital Study Advisory Committee (ASQ, 2009) showed the level of adoption of Lean or Six Sigma practices at US Hospitals. The inability to sustain improvement was cited as one of the greatest challenges to successful deployment of both Lean and Six Sigma deployments. Other challenges include: competition from other initiatives, leadership commitment, availability of resources, motivating employees, expertise and skills, etc. The study also demonstrated that a majority of hospitals participated at the study have applied the following specific tools and techniques of Lean and Six Sigma: Value-stream mapping, 5S, Pareto analysis, Failure Mode and Effect Analysis, Statistical Process Control, Five whys, Seven or Eight Forms of waste, and Visual management.

Feng and Manuel (2008) present the results from a national survey of Six Sigma program in US Healthcare organisations. A total of 56 hospitals responded to this survey of which 15 hospitals are practicing Six Sigma while 41 are non-Six Sigma organisations. Most of the Six Sigma organisations have implemented the program for less than four years, which suggests that Six Sigma program is still in its infancy stage in healthcare organisations. The authors also found that the lack of commitment from leadership is the major resistance or barrier for the 
successful implementation of Six Sigma. The types of projects performed within the healthcare organisations were focused on three categories: Cycle time reduction, process flow improvement; and medical-error reduction

Grove at al. (2010) presented the fundamental challenges identified during a lean implementation in a health visiting service within a large primary care trust in NHS, UK. The authors have utilized a triangulated approach for data collection which included semi-structured interviews, document analysis and participant observation. The challenges to lean transformation from this study were: lack of understanding of what Lean is all about; poor communication; poor leadership; high process variability; determining who the customer is and what do they value?; high process variability, and so on.

The authors also argued that if hospitals wish to deliver world-class healthcare in the face of constrained resources and greater demand, they need to develop a long-term vision and world-class leadership to sustain the initiative and get Lean embedded into the DNA of the healthcare organisations.

De Souza and Pidd (2011) in their study explored the barriers to Lean healthcare based on experience of applying Lean thinking in the UK's NHS. The authors concluded that many of the barriers are people-based or organizational apart from inappropriate jargon and a worry that people will be treated like widgets. Perception that Lean is primarily meant for manufacturing can also be a major barrier to Lean implementation. The authors also observed that functional and professional silos are seen as a major barrier to Lean implementation.

\section{RESEARCH METHODOLOGY}

The fundamental purpose of this study was to "examine the extent to which Lean and Six Sigma methodologies are being implemented within NHS Scotland". In order to do this effectively, the general objectives were further divided into a number of specific research questions as follows.

- What is the current status for the use of Lean and Six Sigma in NHS Scotland?

- To what extent are the NHS Scotland familiar with the tools and techniques of Lean and Six Sigma?

- What benefits have been brought to the NHS Scotland through Lean and Six Sigma strategies?

- What are the Critical Success Factors (CSFs) for implementation of Lean and Six Sigma with NHS Scotland?

- What are the common barriers in the implementation of Lean and Six Sigma methodologies in NHS Scotland?

In order to achieve the research objectives, a survey questionnaire was initially constructed drawing upon prior literature. Given majority of the research questions are 'What' type questions, an exploratory survey research strategy was adopted for data collection (Saunders et al., 2010; Yin, 2009). Survey is perhaps 
the dominant form of data collection in the social sciences, providing for efficient collection of data over broad populations, amenable to administration in person, by telephone, or over the Internet (Easterby-Smith et al. 2008, Saunders et al. 2010, Fowler 2002). Survey questionnaire will allow for the largest amount of data and the most thorough amount of data that can be collected within the boundaries of this study (Fowler, 2002).

Survey questionnaire was first pilot tested with ten participants from NHS and Academics. Based on their comments, five questions were dropped and other eight questions were reworded. A Likert scale of 1-5 was used for critical success factors and tools \& techniques section of the questionnaire. The final questionnaire was mailed out to 800 people in various regions of the National Health Service in Scotland. Of the 800 questionnaires mailed, 90 completed questionnaires across 18 Health Board Regions (HBRs) were returned. This represented a response rate of over $11 \%$, which was rather regarded as satisfactory (Saunders et al., 2010). A total of 12 responses were not useable due to incomplete data. This resulted to only 78 completed questionnaires used in the final analysis of this paper. Table 1 presents the breakdown of respondents who have completed the questionnaire.

Table 1 -Breakdown of respondents to the survey questionnaire

\begin{tabular}{|l|l|}
\hline Respondents (Type) & Frequency \\
\hline Medical Directors & 12 \\
\hline Nurses & 14 \\
\hline Medical Doctors & 6 \\
\hline Clinical Governance Managers & 15 \\
\hline Chief Executives & 5 \\
\hline Quality Improvement Managers & 11 \\
\hline Patient Safety Officers & 4 \\
\hline Lean Champions & 4 \\
\hline Accountants & 4 \\
\hline Others & 3 \\
\hline Total & $\mathbf{7 8}$ \\
\hline
\end{tabular}

\section{FINDINGS FROM THE SURVEY}

\subsection{Current Status of Lean and Six Sigma}

The first part of our investigation was to understand the current quality and process improvement related initiatives utilized by the NHS Scotland. It was found that a number of hospitals are using Kaizen related activities as part of process improvement. Moreover we also found that although Lean has been 
embraced by a number of NHS Trusts in Scotland. However there was a clear lack of evidence in the use of Lean thinking to change the culture of a particular NHS Trust. For many hospitals, we felt that Six Sigma is still new as they are currently tackling several quick-win projects across many hospitals. AS expected, ISO 9001 is the main quality improvement initiative being implemented by the Health Service Executives in many hospitals. Lean has been used for tackling following types of projects in various hospitals, e.g. waiting time reduction in $\mathrm{A} \& \mathrm{E}$; length of stay in $\mathrm{A} \& \mathrm{E}$; throughput of operating theatres; turnaround times at the operation theatres; improved patient flow across the hospital (i.e., streamline cycle from referral to admission); improved discharge management; and improved patient safety and patient satisfaction.

The issue of the key indicators that comes into play when prioritising Lean/Six Sigma projects within the hospitals resulted in many more responses. In terms of the key indicators patient requirements was reported to be important or very important by many of the respondents. At the same time, poorly performing areas in the organisation and multi-disciplinary projects were also indicated as being important indicators for Lean efforts.

It was also noted that many participating hospitals (approximately 70\%) using Lean have had an experience of between 2 and 5 . About $20 \%$ of hospitals have been using Lean between 5 and 7 years and $10 \%$ hospitals have been practicing Lean for over 8 years. Moreover it was interesting to observe that less than $5 \%$ of participating hospitals are using Six Sigma methodology for tackling process variability problems in the hospitals.

\subsection{Tools and Techniques of Lean and Six Sigma}

One of the success factors of both Lean and Six Sigma are their ability to use the toolbox in a systematic and disciplined manner. Table 2 illustrates the most commonly used tools and techniques of Lean and Six Sigma within the NHS Scotland. Respondents were asked to rate the application of Lean and Six Sigma tools and techniques (i.e., usage) on a Likert Scale of 1 to 5 , where ' 1 ' indicates 'never been used' and ' 5 ' indicates 'used continuously'. Similarly, the degree of perceived usefulness was also rated on a scale of 1 to 5 , where ' 1 ' implies 'not useful' and five implies 'extremely useful'.

As can be seen from the Table 2, the least commonly used tools and techniques of Lean/Six Sigma toolbox include: Quality Function Deployment (QFD), Mistake Proofing, SMED, Design FMEA, Process FMEA, Total Productive Maintenance (TPM), Non-Parametric tests, etc. The top five popular tools and techniques of Lean/Six Sigma toolbox include Benchmarking, Brainstorming, Patient Feedback, Process Mapping and Root Cause Analysis. 
Table 2 - Most commonly and least commonly used tools \& techniques of Lean and Six Sigma

\begin{tabular}{|l|l|l|}
\hline Tools/techniques & Usage (Mean) & Usefulness (Mean) \\
\hline Brainstorming & 4 & 3.51 \\
\hline Benchmarking & 3.93 & 3.44 \\
\hline Process Mapping & 3.77 & 3.70 \\
\hline Patient Feedback & 3.51 & 3.14 \\
\hline Cause and Effect & 3.42 & 2.56 \\
\hline Scatter Diagram & 2.93 & 1.79 \\
\hline Hypothesis testing & 2.26 & 1.93 \\
\hline Tally Charts & 1.95 & 1.72 \\
\hline Regression Analysis & 1.93 & 1.77 \\
\hline Pareto Diagram & 0.77 & 0.67 \\
\hline Histogram & 0.65 & 0.42 \\
\hline Quality Costing & 0.49 & 0 \\
\hline Control chart/Run Chart & 0.32 & 0.45 \\
\hline 5S Practice & 0.16 & 0.28 \\
\hline SIPOC & 0.14 & 0.16 \\
\hline Value Stream Mapping & 0.09 & 0.21 \\
\hline Error Proofing & 0.02 & 0.09 \\
\hline Quality Function Deployment (QFD) & 0 & 0 \\
\hline Set up Time Reduction (SMED) & 0 & 0.04 \\
\hline Failure Mode and Effect Analysis (FMEA) & 0 & 0 \\
\hline Non-Parametric tests (Mann-Whitney test) & 0 & 0 \\
\hline Total Productive Maintenance (TPM) & 0 & 0 \\
\hline
\end{tabular}

\subsection{Key Benefits of Lean and Six Sigma}

As the success of Lean and Six Sigma initiatives are focused on the project execution, it was important to understand the areas where the projects are carried out across the participating hospitals. Figure 1 shows the typical benefits of Lean projects carried out across 18 Health Board Regions (HBRs). The areas that have experienced the greatest benefits are reduction in operational costs, reduction in patient waiting times, waste reduction in processes and so on. From the 18 NHS Health Board Regions, we found that over 40 projects were Lean related and about 8 were Six Sigma related. The Six Sigma related projects were focused on reducing the number of medication errors, reducing MRI examination time, pathology laboratory turnaround time, X-ray film defects, etc. 


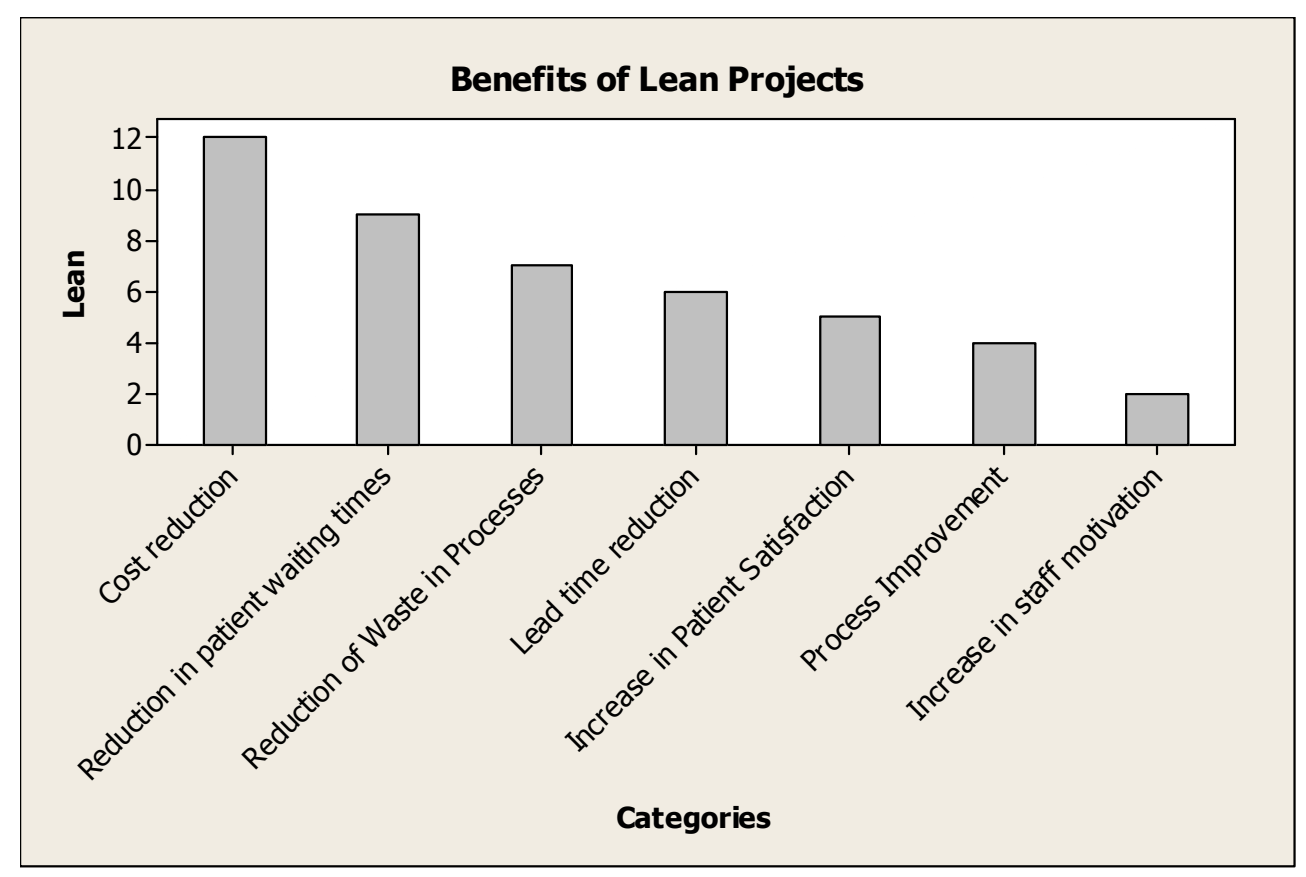

Figure 1 - Typical benefits of Lean projects from the participating hospitals

\subsection{Critical Success Factors (CSFs) for the successful implementation of Lean and Six Sigma Strategies in NHS Scotland}

The idea of identifying the CSFs as a basis for determining the information needs of managers was popularized by Rockart (Rockart, 1979). In the context of Lean and Six Sigma methodologies, CSFs represent the essential ingredients without which the initiative stands little chance of success. The leaders of health care industry should consider the application of Lean and Six Sigma from the perspective of improving the flow, quality and capability of current processes as well as the ability of processes to deliver patient care and safety tomorrow. The following CSFs were perceived to be essential for the successful development and deployment of both Lean and Six Sigma initiatives in NHS Scotland. The respondents were asked to rank the CSFs identified from the existing literature on a scale of 1 to 5 (1= least important, $2=$ less important, $3=$ important, $4=$ very important and $5=$ crucial). The CSFs used in this study were derived from existing literature of TQM and Six Sigma (Adams et al., 2003; Antony and Banuelas, 2002; Antony et al., 2008; Antony et al., 2007; Hilton et al., 2008; Timans et al., 2011; Yusof and Aspinwall, 1999; Badri et al., 1995; Black and Porter, 1996). Table 3 illustrates the CSFs which are essential for the successful introduction of Lean and Six Sigma initiatives in NHS Scotland. 
Table 3 - CSFs for Successful introduction of Lean and Six Sigma

\begin{tabular}{|l|l|l|}
\hline Critical Success Factors (CSFs) & Importance & Practice \\
\hline Focusing on the needs of patients & 5.00 & 3.93 \\
\hline Senior management commitment and involvement & 4.91 & 4.56 \\
\hline $\begin{array}{l}\text { Strong leadership to continuous improvement processes } \\
\text { demonstrated by managers al all levels }\end{array}$ & 4.86 & 3.42 \\
\hline Establishing measurement and feedback systems & 4.58 & 3.91 \\
\hline Appointing a Project Champion/Facilitator & 4.53 & 3.65 \\
\hline Establishing a culture for continuous improvement & 4.51 & 4.02 \\
\hline $\begin{array}{l}\text { Integrating continuous improvement activities interdisciplinary } \\
\text { teams and at all levels }\end{array}$ & 4.49 & 3.19 \\
\hline Focusing on critical processes & 4.33 & 4.21 \\
\hline Focusing on employees & 4.33 & 4.56 \\
\hline Communication with employees & 3.95 & 3.58 \\
\hline $\begin{array}{l}\text { Project Management (good project planning, project tracking, } \\
\text { reviews etc. ) }\end{array}$ & 3.91 & 3.40 \\
\hline $\begin{array}{l}\text { Learning from continuous improvement results automatic capturing } \\
\text { and sharing of learning }\end{array}$ & 3.72 & 3.28 \\
\hline $\begin{array}{l}\text { Including best practice/gold standard achievements documented } \\
\text { quality management system }\end{array}$ & 3.65 & 2.84 \\
\hline Organisation infrastructure (e.g. project champions) & 3.60 & 2.91 \\
\hline Understanding methods, tools and techniques etc. & 3.47 & 3.00 \\
\hline Willingness to take risks & 3.44 & 3.12 \\
\hline $\begin{array}{l}\text { Linking Lean/Six Sigma to business strategy, Government targets, } \\
\text { Financial indicators. }\end{array}$ & 3.14 & 1.77 \\
\hline Training in Lean / Six Sigma & 3.23 & 2.83 \\
\hline
\end{tabular}

Table 3 illustrates the list of Critical Success Factors (CSFs) in terms of importance (this means expected importance of a factor according to people who had participated in the survey) and practice (experienced or perceived importance for a factor). The top five important factors (from a list of 18 factors identified from the literature) perceived by the hospitals based on the study were:

- Senior management commitment and involvement

- Focusing on critical processes for improvement

- Establishing a culture for continuous improvement

- Focusing on the needs of patients

- Establishing measurement and feedback systems

The least important factors perceived by the participating hospitals were: 
- Linking Lean/Six Sigma to business strategy, Government targets, etc.

- Training in Lean/Six Sigma

- Including best practice/gold standard achievements in a documented quality management system

- Organizational infrastructure for Lean/Six Sigma program (e.g.: project champions)

- Understanding methods, tools, techniques, etc. within Lean/Six Sigma (when, where, why, what, how?)

It was very interesting to observe that projects were not selected by critically looking into its alignment with strategic objectives of hospitals or government targets. Moreover, there was very little attention paid to training program related to methodology, tools and techniques of Lean and Six Sigma for solving process and quality problems. We also found that many hospitals did not have a Lean or Continuous Improvement champion to identify, monitor and review the progress of continuous improvement projects. The authors noticed that the participating hospitals did not have a model or roadmap for sustaining the Lean initiative which is absolutely essential in our opinion for embedding Lean/Six Sigma practices into the culture of NHS Scotland.

\subsection{Common Barriers in the successful implementation of Lean and Six Sigma Strategies in NHS Scotland}

There are several barriers and challenges lurking below the surface for health care industry for consideration before the implementation and deployment of Six Sigma business strategy. The respondents were asked to mark the five barriers that they thought were the most important in terms of implementing Lean and Six Sigma. The top five barriers identified for both Lean initiative and Six Sigma initiative are shown in Figure 2 and 3. For Lean initiative, culture and resistance to change was considered as the most important barrier whereas availability of resources and time was deemed to be the most important barrier to the Six Sigma initiative.

The cultural issues of NHS are somewhat very difficult to change overnight. However the author believes the starting point for initiatives such as Lean Six Sigma is to execute a one day Workshop covering management aspects of Six Sigma and some of the key challenges in the context of Healthcare while implementing such an initiative. Availability of resources and time are always an excuse for many public sector organizations. In order to minimize the budget and resources, it is best to train about 5 to 10 top talented people in the organization in the first wave of training. The focus must be on the execution of projects and selection of projects which are aligned with strategic business objectives or government targets. In NHS, it appears that there is clear lack of leadership and strategic vision with regard to continuous business improvement methodologies. The respondents have ranked high on poor training or coaching as one of the common barriers in the execution of Lean and Six Sigma strategy in NHS. 


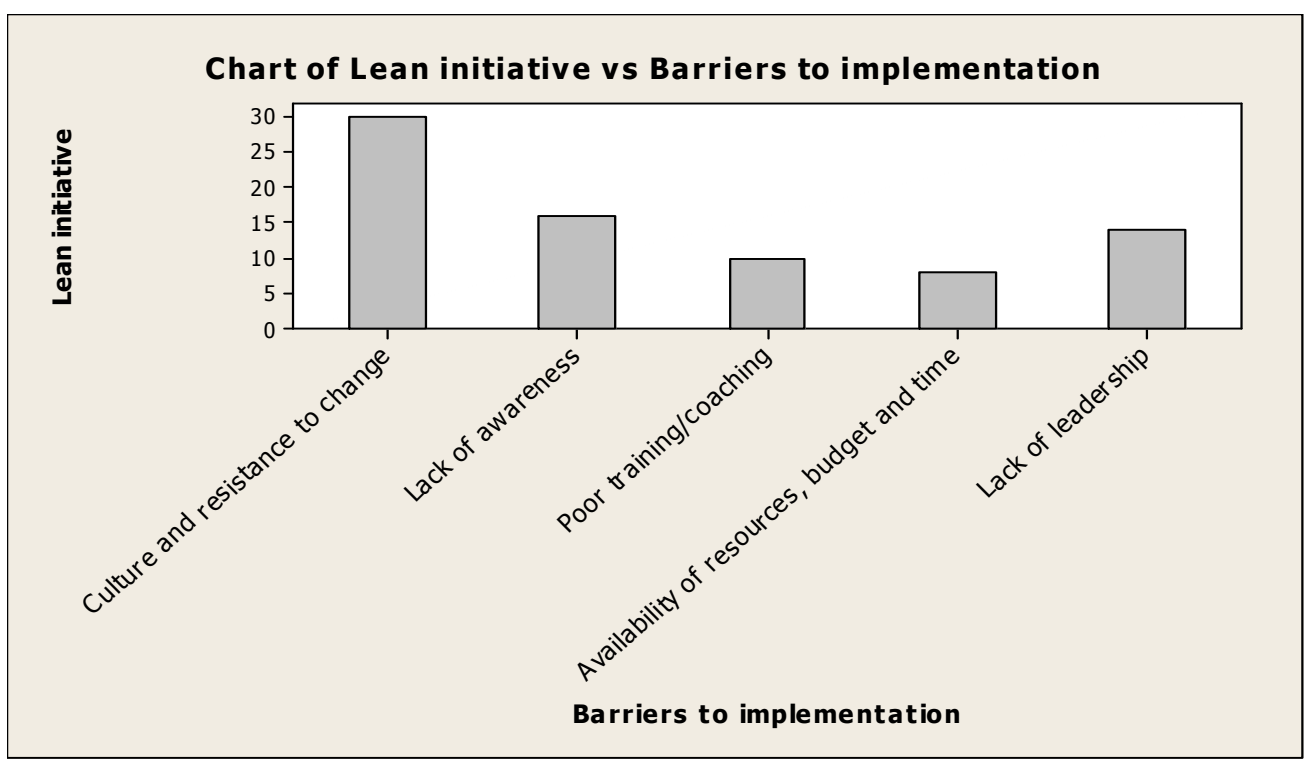

Figure 2 - Barriers to implementation of Lean

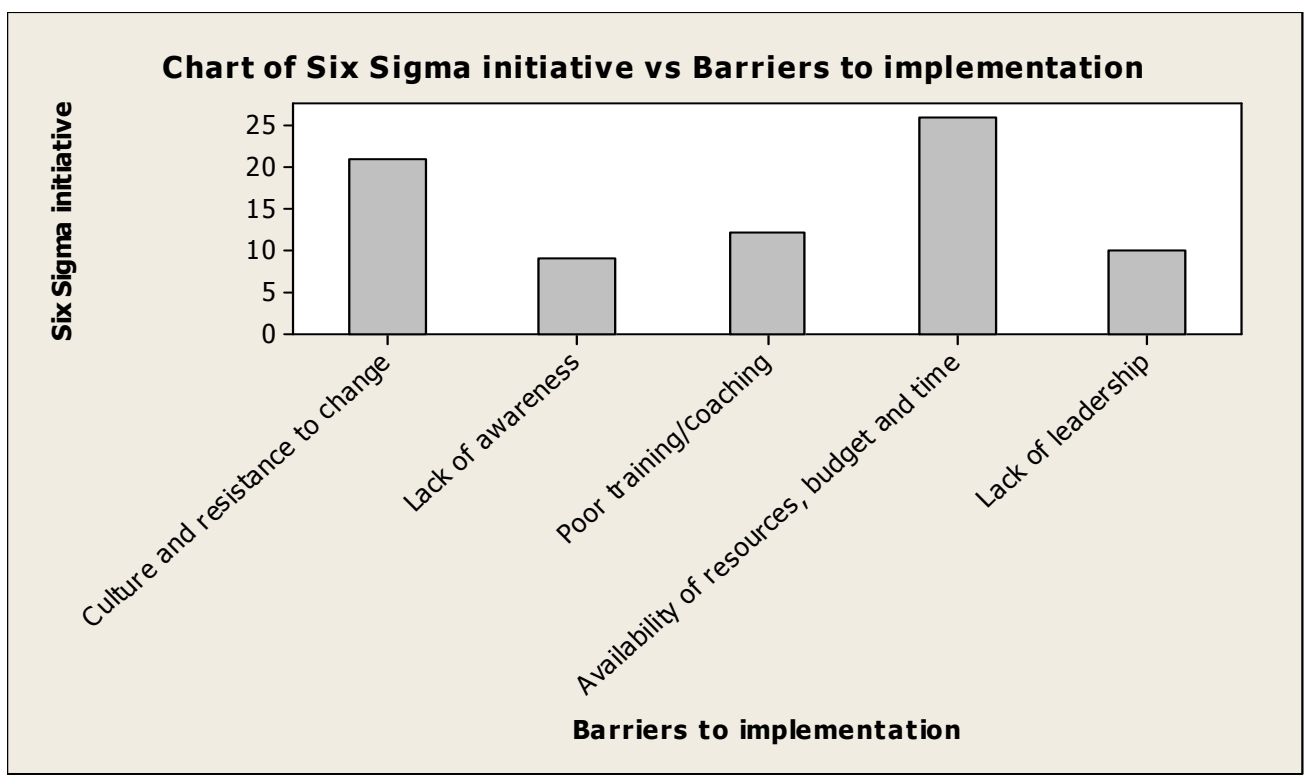

Figure 3 - Barriers to implementation of Six Sigma

In order to gain greater understanding of the status of Lean Six Sigma methodology within NHS Scotland, a number of semi-structured interviews were performed. The participants so far included 2 nurses, 2 Clinical Governance Managers, 1 Clinical Governance Head, 3 Medical Directors and 2 Consultants. Most of the interviews lasted between 30 and 45 minutes. What was interesting, however, from the interviews is that the responses about the use of Lean or Six 
Sigma within NHS Scotland can be grouped into two categories: either the principles are known but not used fully and effectively or when attempts are made to use these principles, the work goes unnoticed by others in the organization. What is interesting from the results of the interviews is that majority of the interviewees actually reported knowledge of quality management tools and techniques. However the findings of the survey seem to suggest that the majority of tools and techniques being used are not seen as being useful by staff.

\section{CONCLUSION AND AGENDA FOR FUTURE RESEARCH}

This paper presents the results of a pilot study on the status of both Lean and Six Sigma initiatives within NHS Scotland. It appears that there is a lack of management commitment within the NHS to institute a culture of using Lean and Six Sigma methodologies and encouraging employees to maintain those efforts. The research on the topic is quite clear that implementing such changes in an organization requires motivation and communication with employees and others who will be directly affected and responsible for taking care of the changes. The results of this study suggest that upper management within the organization is not getting directly involved in the actual implementation of anything that would come close to encouraging widespread use of Lean and Six Sigma across NHS Scotland. The findings of this study serve an important purpose not only for those within NHS Scotland, but really within NHS UK. The ability to successfully implement Lean and Six Sigma cannot be something that is left with only a few people. Instead, it must be something that the entire organization takes seriously. This requires that senior management must provide the resources and training necessary to make it happen. At the same time, there must be encouragement, which can range from financial incentives to simply providing constructive feedback to employees. In the end, it appears that NHS Scotland has quite a long way to go before they can embed Lean or Six Sigma into the fabric of the organisation or even to make Lean or Six Sigma as the way to work. In fact, from the data obtained from this study and the attitudes of staff members, it would seem that major changes in the culture of the organization will be required for any implementation to occur successfully within the next 5 to 10 years. As part of the future research, the authors will be increasing the sample size of the survey and make it as a longitudinal study to assess the status of NHS, Scotland. Moreover we also intend to pursue a number of semi-structured interviews in the forthcoming months to obtain a greater insight into the implementation of these initiatives. The authors would also be keen to develop a bespoke roadmap for the development of Lean and Six Sigma for NHS along with a toolkit which supports the roadmap. 


\section{REFERENCES}

Adams, C. W., Gupta, P., and Wilson, Jr., C. E. (2003), Six Sigma Deployment, Butterworth-Heinemann, Burlington, MA, USA.

Antony, J. and Banuelas, R. (2001), “A Strategy for Survival”, Manufacturing Engineer, Vol. 80, No.3, pp.119-121.

Antony, J. and Banuelas, R. (2002), "Key Ingredients for the effective implementation of Six Sigma program", Measuring Business Excellence, Vol. 6, No. 4, pp. 20-27.

Antony, J., Antony, F.J., Kumar, M., Cho, B.R., (2007), "Six Sigma in Service Organisations: Benefits, Challenges and Difficulties, Common Myths, Empirical Observations and Success Factors", International Journal of Quality and Reliability Management. Vol. 24, No. 3, pp. 294-311.

Antony, J., Kumar, M., and Labib, A., (2008), "Gearing Six Sigma into UK manufacturing SMEs", Journal of the Operational Research Society, Vol. 59, pp. $482-493$.

Antony, J., Krishan, N., Cullen, D., and Kumar, M., (2012), "Lean Six Sigma for Higher Education Institutions (HEIs): Challenges, Barriers, Success Factors, Tools/Techniques", International Journal of Productivity and Performance Management, Vol.61, No.8, [Emerald EarlyCite Article]

ASQ Lean Six Sigma Hospital Study Advisory Committee (2009), "Get your checkup", Quality Progress, August, pp. 44-50.

Badri, M.A., Davis, D., and Davis, D., (1995), "A Study of measuring the Critical factors of Quality Management", International Journal of Quality \& Reliability Management, Vol. 12, No. 2, pp. 36-53.

Bisgaard, S. and De Mast, J., (2006), “After Six Sigma - what is next?", Quality Progress, Vol. 39. No. 1, pp. 30-36.

Black, S.A. and Porter, L.J., (1996), "Identification of the CSFs of TQM", Decision Sciences, Vol. 27, No. 1, pp. 1-21.

Dahlgaard, J. J. and Dahlgaard-Park, S., (2006), "Lean Production, Six Sigma quality, TQM and company culture", The TQM Magazine, Vol. 18, No. 3, pp. 263-281.

De Souzza, L.B. and Pidd, M., (2011), "Exploring the barriers to Lean Health Care implementation", Public Money and Management, Vol.31, No.1, pp. 59-66.

DelliFraine, J.L. and Langabeer, J.R., (2010), "Assessing the Evidence of Six Sigma and Lean in the Health Care Industry", Quality Management Health Care, Vol. 19, No. 3, pp. 211-225.

Easterby-Smith, M., Thorpe, R. and Lowe, A., (2008), Management Research-An Introduction, 3rd ed., Sage Publication, London, UK. 
Feng, Q. and Manuel, C.M. (2008), "Under the Knife:a national survey of Six Sigma program in US Healthcare organisations", International Journal of Healthcare Quality Assurance, Vol. 21, No. 6, pp. 535-547

Fowler, F. J., (2002), Survey Research Methods, $3^{\text {rd }}$ Edition, Sage Publication, London, UK.

George, M. (2002), Lean Six Sigma, McGraw-Hill, NY, USA.

Grove, A.L., Meredith, J.O., MacIntyre, M., Angelis J., and Neailey, K., (2010), "UK health visiting: challenges faced during lean implementation", Leadership in Health Services, Vol. 23, No. 3, pp.204-218.

Hilton, R., Balla, M., and Sohal, A., (2008), "Factors critical to the success of a Six Sigma quality program in an Australian Hospital", TQM and Business Excellence, Vol. 19, No. 9, pp. 887-902.

Kumar, M., Antony, J., Singh, R.K., Tiwari, M.K., and Perry, D., (2006), "Implementing the Lean Six Sigma framework in an Indian SME: a case study", Production Planning and Control, Vol. 17, No. 4, pp. 407-423.

Kumar, M., and Antony, J., and Tiwari, M.K., (2011), "Six Sigma Implementation Framework for SMEs - A roadmap to manage and sustain the change", International Journal of Production Research, Vol.49, No.18, pp.54495467

Lindsay, C.F., Kumar, M., (2012), "How perceptions on Lean thinking affect Lean implementations and their future sustainability", in $4^{\text {th }}$ World P\&OM Conference/19th International Annual EurOMA Conference, Amsterdam, $1^{\text {st }}-5^{\text {th }}$ July 2012.

McAdam, R., Antony, J., Kumar, M., Hazlett, S.A., (2011), “A critique of Six Sigma development in SMEs: An Absorptive Capacity perspective", International Small Business Journal (Online print access- doi: 10.1177/0266242611406945).

Rockart, J.F., (1979), "Chief Executives define their own data needs", Harvard Business Review, Vol. 57, March/April, pp. 81-93.

Saunders, M., Lewis, P., Thornhill,A., (2010), Research Methods for Business Students, $5^{\text {th }}$ edition, Prentice Hall, Essex, UK.

Snee, R., (2010), "Lean Six Sigma - getting better all the time", International Journal of Lean Six Sigma, Vol. 1, No.1, pp. 9-29.

Timans, W., Antony, J., Ahaus, K., Solingen R.V., (2011), "Implementation of Lean Six Sigma in small- and- medium-sized manufacturing enterprises in the Netherlands", Journal of Operations Research Society, Vol. 63, pp. 339-353.

Yin, R.K., (2009), Case study research: design and methods, $4^{\text {th }}$ Edition, Sage Publications, Los Angeles, USA. 
Yusof, S.M. and Aspinwall, E., (1999), "Critical success factors for TQM implementation in small and medium enterprises", Total Quality Management, Vol. 10, Nos. 4 and 5, pp. 803-809.

\section{ABOUT AUTHORS}

Jiju Antony is a Professor of Quality Management at the Department of Design Manufacture Engineering Management, University of Strathclyde, Glasgow, UK. $\mathrm{He}$ is recognised worldwide as a leader in Six Sigma methodology for achieving and sustaining process excellence. He founded the Centre for Research in Six Sigma and Process Excellence (CRISSPE) in 2004, establishing first research centre in Europe in the field of Six Sigma. He is a Fellow of the Royal Statistical Society, Fellow of the Institute for Operations Management and Fellow of the American Society for Quality. He has led a number of Knowledge Transfer projects over the past 8 years and awarded $£ 8$ million from the EU Framework 7 programme as a co-investigator looking at the development of a set of tools and methodologies which will assist European Small and Medium Size enterprises (SMEs) to achieve and maintain worldwide competitiveness. He has authored over 200 journal and conference papers and 5 text books. Jiju has a proven track record for conducting internationally leading research in the field of Quality Management. He is the Editor of the First International Journal of Lean Six Sigma launched in 2010 by Emerald Publishers. He can be reached at jiju.antony@strath.ac.uk.

Maneesh Kumar is a Lecturer of Service Operations \& Lean Six Sigma Trainer at Cardiff Business School, Cardiff University, Wales,UK. Before joining Cardiff, he was a Lecturer at Edinburgh Napier University. He is also visiting faculty at Heriot-Watt University (Edinburgh) and Indian Institute of Management (Ranchi, India). He is an active member of ASQ, EUROMA, CMI, ISPQR, and BAM. Maneesh's research and publications are in the area of Lean Six Sigma (LSS), Agility, and Sustainable Supply Chain Management for both public and private sectors. His research outputs includes an edited book, five edited conference proceedings, two book chapters, twenty six peer reviewed journal publications, fourty seven conference papers, and six white papers. He has been involved in delivering LSS training up to Black Belt level and has facilitated organizations in UK, Belgium, Dubai and India to implement LSS. He is actively involved in LSS research within Public Sector organizations such as the NHS and City Councils. He can be reached at kumarm8@ cardiff.ac.uk. 